ОСОБЕННОСТИ ПРИМЕНЕНИЯ КОМПЛЕКСА ОПЕРАТОРАМИ В
КОФЕИНСОДЕРЖАЩЕГО

В ПРОЦЕССЕ

СУТОЧНОГО

\title{
ДЕЖУРСТВА
}

\author{
В. П. Ганапольский, С. С. Гринчук, В. Н. Болехан, О. В. Извозчикова, \\ О. В. Лучникова, М. К. Ржепецкая, Н. А. Щукина
}

ФГБВОУ ВО «Военно-медицинская академия имени С. М. Кирова» МО РФ, г. СанктПетербург, Россия

Резюме. Исследована работоспособность добровольцев - операторов дежурных смен, подверженных повышенным умственным и психоэмоциональным нагрузкам при длительной операторской работе, с использованием кофеинсодержащего комплекса (жевательной резинки). Выявлено, что при несении дежурства в условиях утомления (состояния монотонии) применение кофеинсодержащего комплекса может приводить к незначительному улучшению субъективного статуса на фоне снижения значений вегетативных показателей сердечно-сосудистой системы (тонуса периферических сосудов) (2 табл., библ.: 8 ист.).

Ключевые слова: кофеинсодержащий комплекс, работоспособность, состояние монотонии, утомление, функциональное состояние организма.

Статья поступила в редакцию 17.10.2017.

\section{APPLICATION FEATURES OF CAFFEINE-CONTAINING COMPLEX BY OPERATORS IN DAILY DUTY}

\section{P. Ganapolsky, S. S. Grinchuk, V. N. Bolekhan, O. V. Izvozchikova, O. V. Luchnikova, M. K. Rzhepetskaya, N. A. Shchukina}

S. M. Kirov Military Medical Academy the Russian Defense Ministry, Saint Petersburg, Russia

Summary: The performance of volunteers-operators of duty shifts, subjected to increased mental and psycho-emotional loads during prolonged operator's performance using a caffeine-containing complex (chewing gum) has been studied. It 
has been revealed that in performing their duty shifts under fatigue conditions (a state of monotony), the use of a caffeine-containing complex can lead to a slight improvement in the subjective status against the background of a decrease in the vegetative parameters values of the cardiovascular system (tone of peripheral vessels) (2 tables, bibliography: 8 refs).

Key words: body functional state, caffeine-containing complex, fatigue, performance, state of monotony.

\section{Article received 17.10.2017.}

\section{ВВЕДЕНИЕ}

Проблема поддержания работо- и боеспособности военнослужащих становится особенно актуальной в условиях интенсивного действия экологопрофессиональных факторов, которые приводят к рассогласованию возможностей организма и требований профессиональной деятельности, что существенно снижает работоспособность военнослужащих.

Один из вариантов поддержания работоспособности фармакологическая коррекция функционального состояния организма.

Для оптимизации уровня работоспособности используются препараты, относящиеся к группе психомоторных стимуляторов. Наиболее распространенным средством коррекции функционального состояния организма в бытовых условиях являются представители группы ксантиновых алкалоидов, в частности кофеин $[1,2]$. Механизм действия данного лекарственного средства основан на двух принципиальных эффектах. Вопервых, это антагонизм рецепторов аденозина, выполняющих функцию торможения в ЦНС и регулирующих сосудистый тонус; во-вторых, угнетение фермента фосфодиэстеразы, метаболизирующего циклический аденозинмонофосфат (цАМФ), приводящее к накоплению в клетке вторичного посредника —цАМФ, и как следствие этого - активация клеточных функций. Данный механизм реализуется посредством следующих основных эффектов: 
умеренного психостимулирующего, венотонического, кардиотонического, секреторного и диуретического [1]. Особенность кофеина - его мозаичный спазмолитический эффект, проявляющийся в прямом воздействии на сосуды сердца, почек, кожи, но опосредованно он сужает сосуды мозга [3].

Учитывая особенности действия кофеина как средства истощающего типа действия в военной медицине, в частности фармакологии здорового человека, его применение рассматривают в аспекте кратковременного повышения операторской работоспособности, при утомлении и сонливости.

В связи с этим актуально исследование характера влияний кофеинсодержащего комплекса (КСК) на функциональное состояние операторов в процессе 24-часового дежурства [4, 5].

\section{МАТЕРИАЛЫ И МЕТОДЫ ИССЛЕДОВАНИЯ}

В исследовании принимали участие 18 добровольцев - операторов сенсомоторного профиля, практически здоровых лиц мужского пола в возрасте 25-45 лет, профессиональная деятельность которых проходила в условиях непрерывного 24-часового дежурства. В ходе исследования изучалось влияние КСК на показатели функционального состояния организма добровольцев и уровень их работоспособности.

Исследование проводилось двойным слепым методом на двух группах добровольцев - операторов дежурных смен. Первая группа (опытная, 9 чел.) получала энергетическую жевательную резинку, содержащую тонизирующий комплекс на основе кофеина (100 мг), вторая (контрольная, 9 чел.) жевательную резинку, не содержащую тонизирующий комплекс.

За час перед заступлением на дежурство и сразу после дежурной смены проводилось комплексное физиологическое, психофизиологическое и психологическое обследование добровольцев-операторов. Прием жевательной резинки осуществлялся двукратно: в 16.00 и 5.00. За 15 мин до приема жевательной резинки и через 45 мин после ее приема оценивались 
субъективное состояние и показатели сердечно-сосудистой системы операторов.

Комплексное обследование было направлено на оценку характеристик организма, обеспечивающих эффективное выполнение ими профессиональных обязанностей, изменение которых может вести к угрозе срыва профессиональной деятельности. Функциональное состояние организма оценивалось по показателям: физиологическим (показатели сердечнососудистой системы: частота сердечных сокращений (ЧСС), систолическое (САД) и диастолическое (ДАД) артериальное давление крови, вариационная пульсометрия); психофизиологическим (определение реакции на движущийся объект (РДО), определение времени простой зрительно-моторной реакции (ПЗМР), определение инкрементного порога критической частоты слияния световых мельканий $($ КЧСМ)); психологическим (показатели субъективной оценки (самочувствие, активность, настроение, жалобы), тест Спилбергера-Ханина, методика структурированного интервью) [6-8].

Эффективность профессиональной деятельности специалистов определялась по прямым показателям операторской работоспособности (время выполнения задач по предназначению, количество ошибочных действий и итоговая экспертная оценка руководителя дежурной смены).

Количественные переменные подвергались анализу в абсолютном выражении. Расчетно-аналитическая часть исследования строилась по принципу практической достоверности. К расчетам был принят единый критический (пороговый) уровень значимости $\alpha=0,05$.

Применялись следующие методы математико-статистического анализа:

- $\varphi$-критерий углового преобразования Фишера (для сравнения долей);

- критерии Манна-Уитни, Вилкоксона (для парного сравнения выборок малого объема либо выборок, отклоняющихся от нормального закона распределения). 


\section{РЕЗУЛЬТАТЫ ИССЛЕДОВАНИЯ}

Значения показателей, полученные до приема жевательной резинки (фоновые показатели), в обеих группах операторов оказались сопоставимыми - не было выявлено статистически значимого различия (табл. 1, 2).

Оиенка физиологических показателей. Показатели ЧСС на протяжении всего периода исследования менялись незначительно. Частотный анализ показал, что в конце смены (через 24 ч) уменьшение ЧСС чаще происходило в опытной группе добровольцев (56 и $11 \%$ соответственно, $\mathrm{p} \leq 0,05)$. В контрольной группе показатели артериального давления изначально были незначительно выше, чем в опытной (см. табл. 1). В процессе исследования значимых изменений артериального давления между сравниваемыми группами не отмечено. Пульсовое давление (ПД) и минутный объем кровообращения (МОК) значимо были выше в контрольной группе как перед первым применением, так и сразу после приема жевательной резинки ( $\mathrm{p}=0,01$ и 0,04 соответственно). К концу смены значимых изменений физиологических показателей ни по сравнению с фоном, ни между группами не выявлено.

Исследование и оценка нейрогуморальной регуляции сердечного ритма у операторов до и после суточного дежурства с применением жевательной резинки проводились с помощью статистического и спектрального анализа вариабельности ритма сердца (ВРС) [6] .

Значения показателей ВРС в исходном состоянии свидетельствовали о появлении признаков напряжения функционального состояния организма операторов контрольной и опытной групп (симпатикотония, напряжение вегетативного баланса, высокий уровень надсегментарных влияний на ВРС). Статистически значимых различий между группами в исходном состоянии и после использования КСК не выявлено (см. табл. 1).

В то же время, по результатам частотного анализа, за весь период исследования в опытной группе по сравнению с контрольной существенно реже происходило уменьшение величины показателей коэффициента вариабельности 
(CV) (56 и 89\% соответственно, p < 0,05) и чаще - показателей индекса вегетативного равновесия (ИВР), вегетативного показателя ритма (ВПР) и индекса напряжения (ИН) (44 и 11\% соответственно, p < 0,05).

Применение КСК способствовало тому, что у операторов опытной группы, в отличие от контрольной, чаще регистрировалось снижение показателей, характеризующих напряжение вегетативного баланса (ИВР, ИН), и реже (и на меньшую величину) увеличивались показатели утомления (ВПР) вегетативной нервной системы. С другой стороны, частотный анализ изменения показателей спектрального анализа ВРС (по показателю CV) выявил наличие высокой степени активации надсегментарных уровней регуляции.

Таким образом, применение КСК у операторов, находящихся на суточном дежурстве, приводило к уменьшению выраженности процессов истощения, при этом за счет подключения надсегментарных уровней регуляции организма повышалась физиологическая цена деятельности.

Оиенка психофизиологических показателей. В ходе исследования была проведена сравнительная оценка подвижности нервных процессов. Подвижность определялась с использованием психофизиологических методов оценки КЧСМ и оценки РДО. Динамика величин психофизиологических показателей представлена в табл. 2. Существенных различий этих показателей в сравниваемых группах операторов выявлено не было.

Оценка функционального состояния центральной нервной системы (ЦНС) операторов проводилась с помощью методики ПЗМР. Величины показателей ПЗМР в контрольной и опытной группах в исходном состоянии составили 242-350 и 238-328 мс соответственно. Значения расчетных критериев ПЗМР операторов в обеих группах в исходном состоянии отражали незначительное снижение уровня работоспособности. Статистически значимых различий между группами в исходном состоянии и при использовании КСК не выявлено (см. табл. 2).

Обследование операторов в конце смены (через 24 ч) показало, что 
операторы, использующие КСК, имели больший латентный период ПЗМР (p = $0,002)$, больший показатель моды $(\mathrm{p}=0,01)$, больший разброс значений ПЗМР $(\mathrm{p}=0,02)$ и меньшее значение функционального уровня системы $(\mathrm{p}=0,01)$ по сравнению с другими операторами. Применение частотного анализа экспериментальных данных показало, что в группе, использующей КСК, чаще наблюдалось увеличение показателя моды (55 и 11\% случаев соответственно, p = 0,01). По показателям ПЗМР было выявлено, что у 44\% операторов, использующих КСК, к концу дежурства наблюдался сниженный уровень работоспособности, в то время как в контрольной группе снижение работоспособности констатировалось только у $11 \%$ операторов.

Таким образом, использование операторами в ходе суточного дежурства КСК приводило к усилению развития процессов утомления и как следствие ухудшению функционального состояния ЦНС.

Оченка психологических показателей. В исходном состоянии операторы обеих групп характеризовались средними значениями показателей самооценки состояния, которые соответствовали нормативным значениям для здоровых людей. Статистически значимых различий показателей в контрольной и опытной группах выявлено не было (см. табл. 2).

Сравнительный анализ данных до и после приема жевательной резинки показал улучшение показателей самочувствия, активности, настроения и их суммарного показателя (по опроснику оценки самочувствия, активности и настроения САН), повышение интереса к работе и снижение напряжения (по анкете самооценки состояния АCC) в опытной группе ( $<<0,05)$.

При сравнении данных субъективной оценки состояния при приеме жевательной резинки в ночное время существенных различий между опытной и контрольной группами выявлено не было.

После суточного дежурства операторы опытной группы отметили улучшение самочувствия по показателю спокойствия и уравновешенности по сравнению с контрольной группой. В 94\% случаев операторы обеих групп 
отметили отсутствие эффекта от применения КСК (по субъективной оценке).

Таким образом, ожидаемого позитивного эффекта от приема КСК во время суточного дежурства операторами не выявлено.

Оиенка экспертных показателей. Анализ прямых показателей операторской работоспособности в период проведения исследования в обеих группах добровольцев значимых различий не выявил.

\section{ЗАКЛЮЧЕНИЕ}

При длительном (24-часовом) несении службы в условиях монотонии применение КСК у специалистов операторского профиля может незначительно улучшать субъективный статус, снижать показатели напряжения вегетативной регуляции сердечно-сосудистой системы и понижать активность нервной системы.

\section{СПИСОК ЛИТЕРАТУРЫ / REFERENCES}

1. Shabanov P. D. Psychopharmacology. Saint Petersburg: ELBI-SPb; 2008. 418. Russian (Шабанов П. Д. Психофармакология. СПб.: ЭЛБИ-СПб; 2008. 418).

2. Smith A., Sutherland D., Christopher G. Effects of repeated doses of caffeine on mood and performance of alert and fatigued volunteers. $J$. Psychopharmacol. 2005 Nov; 19 (6): 620-6.

3. Miller P. E., Zhao D., Frazier-Wood A. C., Michos E. D., Averill M., Sandfort V., Burke G. L., Polak J. F., Lima J. A. C., Post W. S., Blumenthal R. S., Guallar E., Martin S. S. Associations of coffee, tea, and caffeine intake with coronary artery calcification and cardiovascular events. Am. J. Med. 2017; 130 (2): 188-197. DOI: 10.1016/j.amjmed.2016.08.038

4. Knapik J. J., Trone D. W., McGraw S., Steelman R. A., Austin K. G., Lieberman H. R. Caffeine Use among Active Duty Navy and Marine Corps 
Personnel. Nutrients. 2016; 8 (10): 620. Available at: http://www.mdpi.com/20726643/8/10/620 (accessed 12.04.2017). DOI:10.3390/nu8100620

5. Sherman S. M., Buckley T. P., Baena E., Ryan L. Caffeine enhances memory performance in young adults during their non-optimal time of day. Front Psychol. 2016; $7:$ 1764. Available at: https://www.ncbi.nlm.nih.gov/pmc/articles/PMC5107567/ (accessed 17.05.2017). DOI: $10.3389 /$ fpsyg.2016.01764

6. Bayevskiy R. M., Ivanov G. G., Chireykin L. V. Analysis of heart rate variability with the use of various electrocardiographic systems: methodical recommendations. Vestnik aritmologii. 2001; 24: 65-87. Russian (Баевский Р. М., Иванов Г. Г., Чирейкин Л. В. Анализ вариабельности сердечного ритма при использовании различных электрокардиографических систем: методические рекомендации. Вестник аритмологии. 2001; 24: 65-87).

7. Moroz M. P., Chubarov I. V. Methodology for assessing and predicting the performance of human operator. Saint Petersburg: Petrotsentr; 2001. 79. Russian (Мороз М. П., Чубаров И. В. Методология оценки и прогнозирования работоспособности человека-оператора. СПб.: Петроцентр; 2001. 79).

8. Belevitin A. B., ed. Medico-psychological correction of specialists of "power" structures: methodical manual. Saint Petersburg: Aysing; 2010. 268. Russian (Белевитин А. Б., ред. Медико-психологическая коррекция специалистов «силовых» структур: методическое пособие. СПб.: Айсинг; 2010. 268).

\section{ИНФОРМАЦИЯ ОБ АВТОРАХ INFORMATION ABOUT AUTHORS}

Ганапольский Вячеслав Павлович - докт. мед. наук, начальник научно-исследовательского отдела (обитаемости) научно-исследовательского центра, ФГБВОУ ВО «Военно-медицинская академия имени С. М. Кирова» МО РФ, 194044, Россия, г. Санкт-Петербург, ул. Академика Лебедева, д. 6, конт. тел.: +7(921)3311231 
Ganapolsky Vyacheslav P. - M. D., D. Sc. (Medicine), Head of the Scientific Research Department (habitability) of the Research Center, S. M. Kirov Military Medical Academy the Russian Defense Ministry, 6, Akademika Lebedeva str., Saint Petersburg, Russia, 194044, cont. phone: +7(921)3311231

Гринчук Светлана Сергеевна - научный сотрудник научноисследовательской лаборатории (обитаемости объектов) научноисследовательского отдела (обитаемости) научно-исследовательского центра, ФГБВОУ ВО «Военно-медицинская академия имени С. М. Кирова» МО РФ, 194044, Россия, г. Санкт-Петербург, ул. Академика Лебедева, д. 6

Grinchuk Svetlana S. - Scientific researcher of Scientific Research Laboratory (habitation of objects) of the Scientific Research Department (habitability) of the Research Center, S. M. Kirov Military Medical Academy the Russian Defense Ministry, 6, Akademika Lebedeva str., Saint Petersburg, Russia, 194044

Болехан Василий Николаевич - докт. мед. наук, заместитель начальника научно-исследовательского центра, ФГБВОУ ВО «Военномедицинская академия имени С. М. Кирова» МО РФ, 194044, Россия, г. СанктПетербург, ул. Академика Лебедева, д. 6

Bolekhan Vasily N. - M. D., D. Sc. (Medicine), Deputy Head of the Research Center, S. M. Kirov Military Medical Academy the Russian Defense Ministry, 6, Akademika Lebedeva str., Saint Petersburg, Russia, 194044

Извозчикова Ольга Владимировна - канд. мед. наук, начальник научно-исследовательской лаборатории (физиолого-гигиенической оценки экипировки военнослужащих) научно-исследовательского отдела (обитаемости) научно-исследовательского центра, ФГБВОУ ВО «Военномедицинская академия имени С. М. Кирова» МО РФ, 194044, Россия, г. СанктПетербург, ул. Академика Лебедева, д. 6 
Izvozchikova Olga V. - M. D., Ph. D. (Medicine), Head of the Scientific Research Laboratory (physiological and hygienic assessment of military equipment) of the Scientific Research Department (habitability) of the Research Center, S. M. Kirov Military Medical Academy the Russian Defense Ministry, 6, Akademika Lebedeva str., Saint Petersburg, Russia, 194044

Лучникова Ольга Владимировна - научный сотрудник научноисследовательской лаборатории (физиологии военного труда) научноисследовательского отдела (обитаемости) научно-исследовательского центра, ФГБВОУ ВО «Военно-медицинская академия имени С. М. Кирова» МО РФ, 194044, Россия, г. Санкт-Петербург, ул. Академика Лебедева, д. 6

Luchnikova Olga V. - Scientific researcher of the Scientific Research Laboratory (physiology of military labour) of the Scientific Research Department (habitability) of the Research Center, S. M. Kirov Military Medical Academy the Russian Defense Ministry, 6, Akademika Lebedeva str., Saint Petersburg, Russia, 194044

Ржепецкая Марина Кирилловна - старший научный сотрудник научноисследовательского отдела (обитаемости) научно-исследовательского центра, ФГБВОУ ВО «Военно-медицинская академия имени С. М. Кирова» МО РФ, 194044, Россия, г. Санкт-Петербург, ул. Академика Лебедева, д. 6, конт. тел.: +7(951)6614553, e-mail: marrje @ rambler.ru

Rzhepetskaya Marina K. - Senior Scientific researcher of the Scientific Research Department (habitability) of the Research Center, S. M. Kirov Military Medical Academy the Russian Defense Ministry, 6, Akademika Lebedeva str., Saint Petersburg, Russia, 194044, cont. phone: +7(951)6614553, e-mail: marrje@ rambler.ru

Щукина Нелли Алексеевна - научный сотрудник научноисследовательской лаборатории (процессов взаимодействия человека и техники) научно-исследовательского отдела (обитаемости) научно- 
исследовательского центра, ФГБВОУ ВО «Военно-медицинская академия имени С. М. Кирова» МО РФ, 194044, Россия, г. Санкт-Петербург, ул. Академика Лебедева, д. 6

Shchukina Nelli Alekseevna - Scientific researcher of the Scientific Research Laboratory (processes of interaction of man and technology) of the Research Department (habitability) of the Research Center, S. M. Kirov Military Medical Academy the Russian Defense Ministry, 6, Akademika Lebedeva str., Saint Petersburg, Russia, 194044 
Сравнительный анализ групп операторов на различных сроках суточного дежурства по физиологическим показателям (ранговый критерий Манна-Уитни)(Верст.! Выравнивание в табл. по 1-й строке!)

\begin{tabular}{|c|c|c|c|c|c|c|c|c|}
\hline \multirow{3}{*}{$\begin{array}{c}\text { Показатель, } \\
\text { ед. изм. }\end{array}$} & \multicolumn{8}{|c|}{ Описательные статистики Ме ( $\mathbf{x}_{\min }$; $\mathbf{x}_{\max }$} \\
\hline & \multicolumn{2}{|c|}{ фон } & \multicolumn{2}{|c|}{16.00 ч } & \multicolumn{2}{|c|}{16.45 ч } & \multicolumn{2}{|c|}{9.00 ч } \\
\hline & $\begin{array}{c}\text { Контрольная } \\
\text { группа } \\
(\mathbf{n}=9)\end{array}$ & $\begin{array}{c}\text { Опытная } \\
\text { группа } \\
(\mathrm{n}=9)\end{array}$ & $\begin{array}{c}\text { Контрольная } \\
\text { группа } \\
(\mathbf{n}=9)\end{array}$ & $\begin{array}{c}\text { Опытная } \\
\text { группа } \\
(\mathbf{n}=9)\end{array}$ & $\begin{array}{c}\text { Контрольная } \\
\text { группа } \\
(\mathbf{n}=9)\end{array}$ & $\begin{array}{c}\text { Опытная } \\
\text { группа } \\
(\mathbf{n}=9)\end{array}$ & $\begin{array}{c}\text { Контрольная } \\
\text { группа } \\
(\mathbf{n}=9)\end{array}$ & $\begin{array}{c}\text { Опытная } \\
\text { группа } \\
(\mathrm{n}=9)\end{array}$ \\
\hline ЧСС, уд/мин & $80(74 ; 100)$ & $78(64 ; 94)$ & $80(64 ; 86)$ & $78(60 ; 90)$ & $78(68 ; 88)$ & $74(64 ; 86)$ & $84(76 ; 100)$ & $82(58 ; 96)$ \\
\hline САД, мм рт. ст. & $135(110 ; 160)$ & $\begin{array}{c}125(105 ; \\
160)\end{array}$ & $135(125 ; 170)$ & $\begin{array}{c}128(115 ; \\
160)\end{array}$ & $145(125 ; 150)$ & $\begin{array}{c}130(100 ; \\
150)\end{array}$ & $130(110 ; 145)$ & $\begin{array}{c}125(110 ; \\
160)\end{array}$ \\
\hline ДАД, мм рт. ст. & $85(65 ; 110)$ & $80(60 ; 120)$ & $80(66 ; 100)$ & $80(68 ; 125)$ & $80(72 ; 95)$ & $80(70 ; 120)$ & $85(75 ; 90)$ & $84(70 ; 110)$ \\
\hline ПД, мм рт. ст. & $45(30 ; 70)$ & $45(30 ; 55)$ & $59(50 ; 70)$ & $50 *(35 ; 60)$ & $55(50 ; 70)$ & $\mathbf{4 5}^{*}(30 ; 65)$ & $40(30 ; 60)$ & $50(20 ; 55)$ \\
\hline МОК, мл & $\begin{array}{c}3505(2337 ; \\
5460)\end{array}$ & $\begin{array}{c}3491(2229 ; \\
4615)\end{array}$ & $\begin{array}{c}4174(2909 ; \\
4991)\end{array}$ & $\begin{array}{c}\text { 3709* (1916; } \\
4812)\end{array}$ & $\begin{array}{c}4025(3250 ; \\
4991)\end{array}$ & $\begin{array}{c}\text { 3040* }(1600 \\
4277)\end{array}$ & $\begin{array}{c}3636(2280 \\
5009)\end{array}$ & $\begin{array}{c}3557,4 \\
(1840 ; 4626)\end{array}$ \\
\hline \multicolumn{9}{|c|}{$B P C$} \\
\hline $\mathrm{CV}, \%$ & $6,5(2,6 ; 11,5)$ & $\begin{array}{c}5,99(3,6 ; \\
10,4)\end{array}$ & - & - & - & - & $4,27(2,1 ; 7,4)$ & $5,3(3,5 ; 7,1)$ \\
\hline ИВР, усл. ед. & $154(36,7 ; 628)$ & $\begin{array}{c}198(67,1 ; \\
527)\end{array}$ & - & - & - & - & $327(139 ; 1175)$ & $211(15 ; 448)$ \\
\hline ВПР, усл. ед. & $5,9(2,3 ; 11,7)$ & $\begin{array}{c}5,56(3,4 ; \\
11,3)\end{array}$ & - & - & - & - & $9,2(4,7 ; 20,2)$ & $\begin{array}{c}6,9(4,3 ; \\
10,7)\end{array}$ \\
\hline
\end{tabular}




\begin{tabular}{|c|c|c|c|c|c|c|c|c|}
\hline ИН, усл. ед. & $115(22,1 ; 395)$ & $\begin{array}{c}137(47,6 \\
370)\end{array}$ & - & - & - & - & $215(93,4 ; 963)$ & $\begin{array}{c}159(89,6 \\
310)\end{array}$ \\
\hline
\end{tabular}

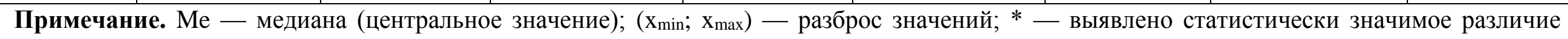
между показателями в опытной и контрольной группах $(\mathrm{p} \leq 0,05)$.

Таблий 2

Сравнительный анализ групп операторов на различных сроках суточного дежурства по психофизиологическим и психологическим показателям (ранговый критерий Манна-Уитни)

\begin{tabular}{|c|c|c|c|c|c|c|c|c|}
\hline \multirow{3}{*}{$\begin{array}{l}\text { Показатель, } \\
\text { ед. изм. }\end{array}$} & \multicolumn{8}{|c|}{ Описательные статистики Ме ( $\left.x_{\min } ; x_{\max }\right)$} \\
\hline & \multicolumn{2}{|c|}{ фон } & \multicolumn{2}{|c|}{16.00 ч } & \multicolumn{2}{|c|}{16.45 ч } & \multicolumn{2}{|c|}{9.00 ч } \\
\hline & $\begin{array}{c}\text { Контрольная } \\
\text { группа } \\
(\mathbf{n}=9)\end{array}$ & $\begin{array}{c}\text { Опытная } \\
\text { группа } \\
(\mathbf{n}=9)\end{array}$ & $\begin{array}{c}\text { Контрольная } \\
\text { группа } \\
(\mathbf{n}=9)\end{array}$ & $\begin{array}{c}\text { Опытная } \\
\text { группа } \\
(\mathbf{n}=9)\end{array}$ & $\begin{array}{c}\text { Контрольная } \\
\text { группа } \\
(\mathbf{n}=9)\end{array}$ & $\begin{array}{c}\text { Опытная } \\
\text { группа } \\
(\mathbf{n}=9)\end{array}$ & $\begin{array}{c}\text { Контрольная } \\
\text { группа } \\
(\mathbf{n}=9)\end{array}$ & $\begin{array}{c}\text { Опытная } \\
\text { группа } \\
(\mathbf{n}=9)\end{array}$ \\
\hline \multicolumn{9}{|c|}{ Психофизиологические показатели } \\
\hline \multicolumn{9}{|c|}{ KЧCM } \\
\hline КЧСМ (среднее & $33,8(27,5 ; 44)$ & $32,8(28,4$ & - & - & - & - & $34,9(30,8 ; 44)$ & $33,3(27,8$ \\
\hline
\end{tabular}




\begin{tabular}{|c|c|c|c|c|c|c|c|c|}
\hline возрастание), Гц & & 36) & & & & & & 40) \\
\hline \multicolumn{9}{|c|}{$\Pi 3 M P$} \\
\hline ЛП, мс & $273(242 ; 350)$ & $\begin{array}{c}294(238 ; \\
328)\end{array}$ & $285(275 ; 305)$ & $\begin{array}{c}280,5(257 ; \\
345)\end{array}$ & $270(253 ; 315)$ & $\begin{array}{c}288(252 ; \\
368)\end{array}$ & $274(258 ; 294)$ & $\begin{array}{c}\text { 315* }(238 \\
343)\end{array}$ \\
\hline $\begin{array}{l}\text { Функциональный } \\
\text { уровень системы, } \\
\text { усл. ед. }\end{array}$ & $2,7(2,2 ; 2,9)$ & $2,5(2,3 ; 2,3)$ & $2,6(2,4 ; 2,8)$ & $2,6(2,3 ; 2,7)$ & $2,7(2,5 ; 2,8)$ & $0,3(0,2 ; 0,3)$ & $2,7(2,6 ; 2,9)$ & $\begin{array}{c}\mathbf{2 , 5} *(2,2 \\
3,0)\end{array}$ \\
\hline \multicolumn{9}{|c|}{ Психологические показатели } \\
\hline \multicolumn{9}{|c|}{ Самооценка субъективного состояния } \\
\hline $\begin{array}{l}\text { Самочувствие, } \\
\text { баллов }\end{array}$ & $5,1(3,3 ; 6,6)$ & $6,2(4,7 ; 6,7)$ & $4,8(4,0 ; 6,0)$ & $6,1(5,0 ; 7,0)$ & $4,9(3,8 ; 5,9)$ & $\begin{array}{c}6,4 *(5,4 \\
6,8)\end{array}$ & $4,7(3,4 ; 5,7)$ & $5,0(3,2 ; 6,2)$ \\
\hline $\begin{array}{l}\text { Активность, } \\
\text { баллов }\end{array}$ & $4,6(3,3 ; 6,6)$ & $5,9(4,6 ; 6,4)$ & $4,7(3,9 ; 6,2)$ & $5,9(5,0 ; 6,6)$ & $4,4(3,9 ; 6,0)$ & $\begin{array}{c}\mathbf{6 , 0} *(5,0 \\
6,5)\end{array}$ & $4,0(3,3 ; 5,1)$ & $4,4(3,1 ; 5,8)$ \\
\hline $\begin{array}{l}\text { Настроение, } \\
\text { баллов }\end{array}$ & $5,3(4,0 ; 7,0)$ & $6,4(4,7 ; 6,8)$ & $5,3(4,0 ; 6,9)$ & $6,6(5,7 ; 6,9)$ & $5,3(3,9 ; 6,4)$ & $\begin{array}{c}\mathbf{6 , 6} \mathbf{6}^{*}(5,6 \\
7,0)\end{array}$ & $5,6(4,0 ; 6,1)$ & $5,9(5,0 ; 6,5)$ \\
\hline $\mathrm{CAH}_{\mathrm{cp}}$, баллов & $4,9(3,5 ; 6,7)$ & $6,2(4,7 ; 6,6)$ & $4,7(4,0 ; 6,4)$ & $6,2(5,3 ; 6,8)$ & $4,7(3,9 ; 6,1)$ & $\begin{array}{c}\mathbf{6 , 5} *(5,5 \\
6,6)\end{array}$ & $4,6(3,6 ; 5,6)$ & $5,1(3,8 ; 5,9)$ \\
\hline \multicolumn{9}{|c|}{ Оченка самочувствия } \\
\hline Бодрость, баллов & $5,0(4,0 ; 7,0)$ & $6,0(3,0 ; 7,0)$ & $6,0(4,0 ; 6,0)$ & $6,0(3,0 ; 7,0)$ & $6,0(4,0 ; 7,0)$ & $6,0(4,0 ; 7,0)$ & $5,0(3,0 ; 6,0)$ & $6,0(2,0 ; 7,0)$ \\
\hline $\begin{array}{l}\text { Интерес к работе, } \\
\text { баллов }\end{array}$ & $5,0(4,0 ; 7,0)$ & $6,0(5,0 ; 7,0)$ & $5,0(4,0 ; 7,0)$ & $6,0(5,0 ; 7,0)$ & $5,0(3,0 ; 6,0)$ & $\begin{array}{c}\mathbf{6 , 0} *(4,0 \\
7,0)\end{array}$ & $4,0(1,0 ; 6,0)$ & $5,0(2,0 ; 7,0)$ \\
\hline Внимание, баллов & $6,0(3,0 ; 7,0)$ & $6,0(5,0 ; 7,0)$ & $5,0(3,0 ; 7,0)$ & $6,5(5,0 ; 7,0)$ & $6,0(4,0 ; 7,0)$ & $6,0(4,0 ; 7,0)$ & $5,0(3,0 ; 6,0)$ & $6,0(4,0 ; 7,0)$ \\
\hline
\end{tabular}




$\left.\begin{array}{|l|c|c|c|c|c|c|c|}\hline \begin{array}{l}\text { Спокойствие, } \\ \text { баллов }\end{array} & 6,0(4,0 ; 7,0) & 7,0(4,0 ; 7,0) & 5,0(4,0 ; 7,0) & 6,0(5,0 ; 7,0) & 5,0(4,0 ; 6,0) & \mathbf{6 , 0}(4,0 ; \\ 7,0) & 5,0(4,0 ; 6,0) & \mathbf{6 , 0} *(5,0 ; \\ 7,0)\end{array}\right)$


